\title{
European Portuguese Version of the Clinical Frailty Scale: Translation, Cultural Adaptation and Validation Study
}

\author{
Versão Portuguesa da Europa da Escala de Fragilidade \\ Clínica: Estudo de Tradução, Adaptação Cultural e \\ Validação
}

Mário PEREIRA PINTO $\triangle^{1,2}$, Sónia MARTINS ${ }^{2,3}$, Edgar MESQUITA4 ${ }^{4}$, Lia FERNANDES ${ }^{2,3,5}$

Acta Med Port 2021 Nov;34(11):749-760 - https://doi.org/10.20344/amp.14543

\section{ABSTRACT}

Introduction: This study aims to describe the translation and adaptation of the European Portuguese Clinical Frailty Scale and assess its convergent validity and test-retest reliability.

Material and Methods: This validation study included a sample of elderly people admitted in two convalescence units from the National Network of Integrated Continuous Care in Northern Portugal and followed in two outpatient clinics of social solidarity institutions. Convergent validity of the scale was evaluated, against Tilburg Frailty Indicator. Test-retest reliability, sensitivity and specificity were assessed.

Results: Overall, 51 patients were included (mean age $=78$ years old). The Clinical Frailty Scale identified $43.1 \%$ patients with frailty Kappa values for test-retest reliability (non-frail/frail) was 1.00. The intraclass correlation coefficient for the 9-point total scale was 0.999 . A correlation between Clinical Frailty Scale and Tilburg Frailty Indicator was also found $(r s=0.683 ; p<0.001)$. The Cohen's kappa coefficient was 0.423 in the agreement analysis between these scales. The results for sensitivity and specificity defined that $62.0 \%$ of patients were true positives and $81.8 \%$ true negatives. The scale accuracy determined by the receiver operating characteristics curve analysis was 0.782

Discussion: This scale showed an excellent test-retest reliability. Robust results on convergent validity were also achieved, with a moderate correlation and agreement with the Tilburg Frailty Indicator, showing good sensitivity and accuracy, as well as high specificity. Conclusion: This version has an excellent test-retest reliability and good convergent validity, and is both a reliable and valid test for application in clinical practice for assessing Portuguese elderly population admitted in convalescence units and outpatient clinics.

Keywords: Cross-Cultural Comparison; Frail Elderly; Frailty; Geriatric Assessment; Portugal; Surveys and Questionnaires; Translating

\section{RESUMO}

Introdução: Este estudo tem como objetivo descrever a tradução e adaptação da versão Portuguesa da Clinical Frailty Scale e avaliar a validade convergente e fiabilidade teste-reteste.

Material e Métodos: Este estudo de validação incluiu idosos internados em duas unidades de convalescença da Rede Nacional de Cuidados Continuados Integrados no Norte de Portugal e seguidos em consulta de ambulatório de Instituições de solidariedade social. A validade convergente desta escala foi avaliada, comparando-a com o Tilburg Frailty Indicator. A fiabilidade teste-reteste, sensibilidade e especificidade foram testadas.

Resultados: Foram incluídos 51 doentes (idade média $=78$ anos). A escala identificou 43,1\% idosos com fragilidade. Na fiabilidade teste-reteste foi encontrado um kappa = 1 (não-frágil/frágil). O coeficiente de correlação intraclasse para o total da escala de nove pontos foi 0,999. Foi encontrada uma correlação entre a Clinical Frailty Scale e o Tilburg Frailty Indicator $(r s=0,683 ; p<0,001)$. 0 coeficiente Cohen's kappa foi 0,423 na análise da concordância entre estas escalas. Os resultados de sensibilidade e especificidade definiram que $62,0 \%$ dos pacientes eram verdadeiros positivos e $81,8 \%$ verdadeiros negativos. A precisão, determinada pela análise da curva de características receptor-operador, foi de 0,782 .

Discussão: A escala revelou uma excelente fiabilidade teste-reteste, bons resultados de validade convergente, boa correlação e um nível de concordância moderado com o Tilburg Frailty Indicator, demonstrando boa sensibilidade, precisão, e elevada especificidade. Conclusão: Esta versão da escala demonstra excelente fiabilidade teste-reteste e boa validade convergente, sendo um teste fiável e válido para aplicação na prática clínica na avaliação da população idosa portuguesa admitida em unidades de convalescença e em unidades de ambulatório.

Palavras-chave: Avaliação Geriátrica; Comparação Transcultural; Fragilidade; Idoso Fragilizado; Inquéritos e Questionários; Portugal; Tradução

\section{INTRODUCTION}

Aging in humans is inevitable and inexorable, occurring as a series of small steps, first causing cellular damage, and then affecting tissues and organs, which is also

true for the brain. Cumulative decline in many physiological systems and the increased risk of vulnerability resulting from the ageing process is conceptualised as frailty. Elderly

\footnotetext{
1. Programa Doutoral em Gerontologia e Geriatria. Instituto de Ciências Biomédicas Abel Salazar. Porto. Portugal.

2. Centro de Investigação em Tecnologias e Serviços de Saúde. Faculdade de Medicina. Universidade do Porto. Porto. Portugal.

3. Departamento de Neurociências Clínicas e Saúde Mental. Faculdade de Medicina. Universidade do Porto. Porto. Portugal.

4. Departamento de Estatística. Instituto de Saúde Pública. Universidade do Porto. Porto. Portugal.

5. Serviço de Psiquiatria. Centro Hospitalar Universitário São João. Porto. Portugal.

$\triangle$ Autor correspondente: Mário Pereira Pinto. mariojcpinto@gmail.com

Recebido: 11 de julho de 2020 - Aceite: 29 de dezembro de 2020 - First published: 09 de fevereiro de 2021 - Online issue published: 02 de novembro de 2021 Copyright $\odot$ Ordem dos Médicos 2021
} 
people with frailty typically have weak muscles (sarcopenia) are frequently prescribed five or more medications (polypharmacy) and may also have visual/hearing and cognitive impairment, and are therefore especially vulnerable to inhospital harm.

Frailty is considered a multidimensional vulnerable condition, including physiological loss of energy, physical ability or cognitive function, with decline of wellbeing, and can lead to vulnerability. Therefore, it is associated with adverse health outcomes, higher rates of dependency, institutionalization and mortality among elders., ${ }^{1,2}$

Several definitions of frailty have been developed, with some approaching impairments, while others include physiologic or energy dysregulated components like weight loss, exhaustion, weakness, slowness and reduced physical activity. ${ }^{3}$ However, it is recognized that frailty is associated with vulnerability, either promoted by ageing, genetic, environmental or lifestyle factors. ${ }^{4}$

The European Union considers that frail individuals are more likely to be hospitalized or institutionalized in nursing homes, with decreased quality of life and should be screened for frailty, especially if older than 70 years old or having chronic diseases. ${ }^{2,5}$ Moreover, frailty is a dynamic process, changeable over time and influenced by interventions, with potentially preventable negative consequences. ${ }^{6}$ Evidence suggests that it is possible to positively change frailty with the increase of vitamin $D$ levels, protein-calorie supplementation, physical activity and polypharmacy reduction. $^{2}$

There are more than 70 different tools to assess frailty but few are validated. ${ }^{7}$ Taking this into consideration, simple rapid screening tests have been developed and validated to allow physicians to rapidly recognize frailty, particularly before patients become functionally dependent. ${ }^{7,8}$ In fact, some are focused mainly on the physical component of frailty, separating it from disability and comorbidity, like the 'phenotype of frailty' model (the FRAIL and Fried scales) while others are based on conditions or disabilities and tend to emphasize the number rather than the nature of deficits, namely the 'accumulation of deficits' model (SHARE frailty index). ${ }^{7,9}$ Another approach is the 'multidimensional' model (Tilburg and Groningen Frailty Indicators), ${ }^{10,11}$ which defines frailty in a more global way, in particular as a dynamic state of loss affecting cognitive and/or psychosocial domains. ${ }^{11,12}$ Other instruments, such as the Clinical Frailty Scale (CFS), consider primarily the presence of disability. ${ }^{1}$

There is a limited number of validated tools for frailty assessment for the European Portuguese language. In fact, the psychosocial model scales Tilburg Frailty Indicator $(\mathrm{TFI})^{10,12}$ and the Groningen Frailty Indicator $(\mathrm{GFI})^{11,13}$ are well known, and are being translated and adapted to European Portuguese.

However, there is a lack of a clinical and non-time-consuming scale that can be applied to routine clinical practice. As a result, frailty is usually underdiagnosed by hospitals or primary health care clinicians. Considering that frailty can be prevented, its effective assessment is of utmost impor- tance to plan interventions and identify patients at risk. ${ }^{7}$

Bearing this in mind, the present study aims to describe the translation and adaptation process of the Clinical Frailty Scale (CFS) into European Portuguese. It also aims to assess the psychometric proprieties of this version, namely the convergent validity and test-retest reliability. There are several reasons for choosing this tool. Firstly, based on the results from its characteristics, it is easy and quick to use, there are no additional tools required, it is supported by a visual diagram, it identifies a prior weakness through a cut-off point and can be applied to both hospital and community settings. These characteristics may facilitate the future incorporation of CFS into routine screening and clinical decision-making algorithms, namely in the most commonly used electronic health record software used in Portuguese primary health care $\left(\mathrm{SClínico}^{\circledR}\right)$, where no frailty screening tool is available at all. In fact, only the Barthel Index is accessible in this software, for evaluation of the basic activities of daily living, and is partially helpful in the physician assessment of frailty. In this context, a recent study in the $\mathrm{UK}^{14}$ developed and validated an electronic frailty index for use in routine primary care, with 900000 patients, showing that this index has robust predictive validity for outcomes of nursing home admission, hospitalisation and mortality.

Secondly, the CFS has been validated in many countries - Canada, ${ }^{1}$ Brazil, ${ }^{15}$ Switzerland (French language), ${ }^{16}$ China $^{17}$ and Singapore ${ }^{18}$ - showing good reliability, validity and sensitivity. Thirdly, the CFS is based on a holistic view of the patient, by focussing on their overall health and ability to perform daily activities. Furthermore, this scale does not focus on attitudes concerning health but on the individual's functional status, as opposed to other frailty scales. ${ }^{15}$ In addition, the CFS is a judgment scale and was used to stratify fragility in acute surgical care, ${ }^{19}$ acute medicine,${ }^{20}$ screening in community and caregivers, ${ }^{21}$ in the evaluation of hospital outcomes, ${ }^{22}$ in dialysis ${ }^{23}$ and in cancer. ${ }^{24}$

\section{MATERIAL AND METHODS}

\section{Sample and design}

This is a validation study with a cross-sectional and longitudinal design, which included a sample of elderly patients admitted into two convalescence units from the National Network of Integrated Continuous Care (Rede Nacional de Cuidados Continuados Integrados) in Northern Portugal and followed in two outpatient clinics of Social Solidarity Institutions for elderly people.

Data collection was carried out between April $12^{\text {th }}$ and May $12^{\text {th }}$, 2019.The inclusion criteria were age over 65 . Patients with Glasgow Coma Scale $\leq 11$ points or unable to communicate (e.g., altered language skills or deafness) were excluded. For the study population, 81 potential participants were identified. A non-probability sample of 51 elders was enrolled and considered for the test-retest reliability of the CFS. The data was collected anonymously in two assessments, one to two weeks apart. The sample power was determined post-hoc, based on an expected intraclass correlation coefficient (ICC) power of 0.90 and an expected 
Spearman correlation power of $r s=0.50$, as null hypothesis. For both the ICC and the Spearman correlation, the sample size was $n=51$ and the selected significance level was $p=0.05$. Both analyses were based on a significance level of 0.05 .

The study was conducted in accordance with the Declaration of Helsinki and approved by the Ethics Committee of the Northern Portugal Regional Health Administration (ARS
Norte) and by the institutions where the surveys were applied. Informed consent was obtained from all subjects or their relatives, if the patient was unable to decide for him/ herself.

\section{Clinical Frailty Scale}

The CFS, developed by Rockwood, ${ }^{1}$ is a well validated instrument, and a scale with both clinical/functional and

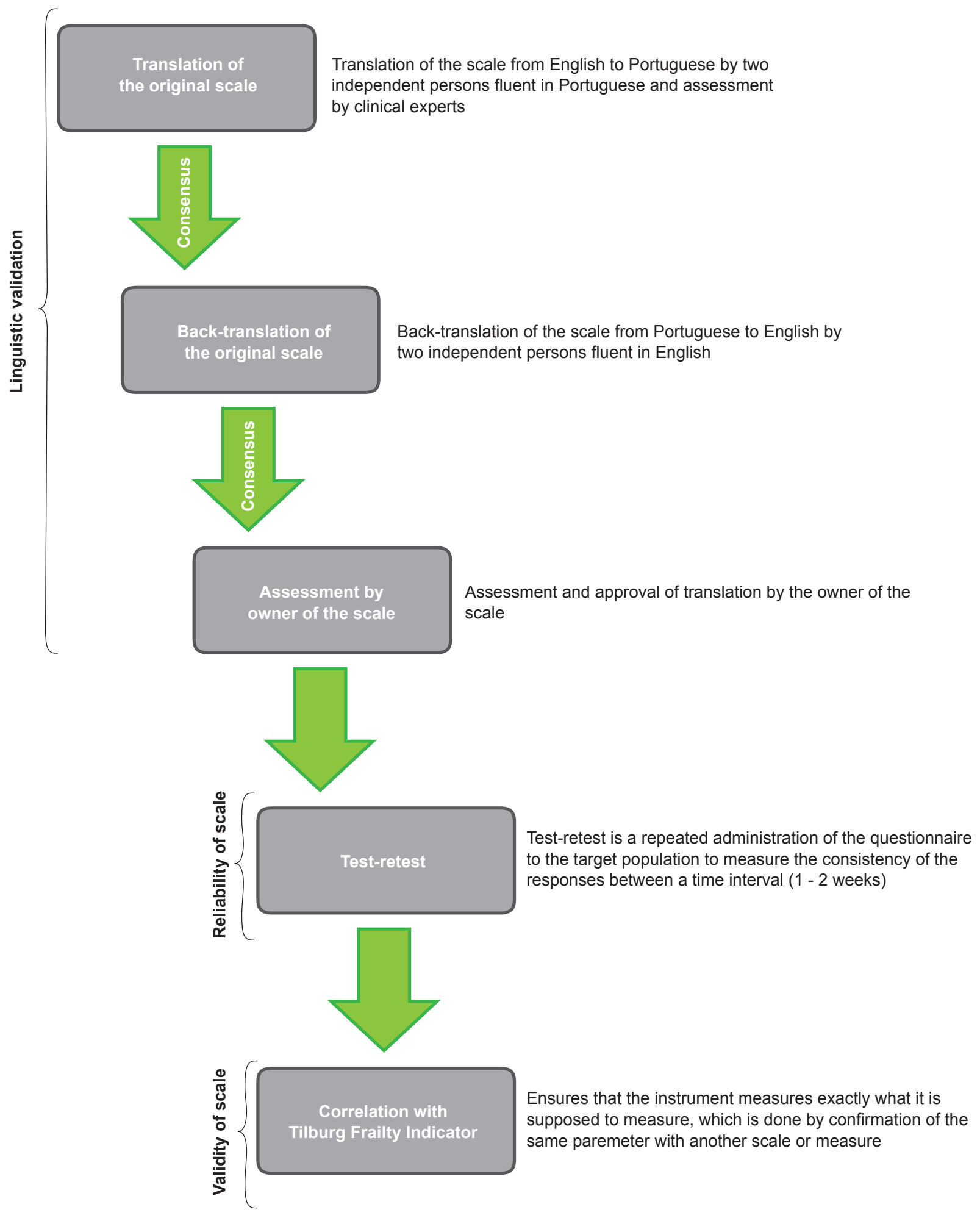

Figure 1 - Flowchart of the CFS translation and validation process 
cognitive items, having been designed to assess the degree of vulnerability of an individual based on clinical judgment, including cognition, mobility, functionality and comorbidities, in view of history and physical examination carried out by healthcare professional. ${ }^{5,18}$ The original version of CFS, published in 2005, classified frailty into seven grades, the highest being 'severe frailty'. Later, in 2007, the scale was expanded to the present 9-point scale with: 'severely frail', 'very severely frail' and 'terminally ill,' distinguished as clinically distinct groups. Since then, the CFS scores patients in nine categories: 1 - very fit, 2 - well, 3 - managing well, 4 vulnerable, 5 - mildly frail, 6 - moderately frail, 7 - severely frail, 8 - very severely frail and 9 - terminally ill, and added three degrees of dementia classification: mild, moderate and severe. Each category of the scale has a written clinical descriptor and a pictograph to assist with the classification of frailty ${ }^{1,7}$. Additionally, for people with dementia, the degree of frailty corresponds to the degree of dementia. Patients with a score $\geq 5$ are considered frail. ${ }^{7}$ The CFS scores were stratified into three groups, based on the CFS validation study: one to three were 'not frail', four and five were 'at risk to mildly frail' and six to nine were 'frail'. The 'at risk to mildly frail' group was divided into 'vulnerable' (CFS 4) and 'mildly frail' (CFS 5). ${ }^{1}$

The cut-off point is in category five, defining non-frail from one to three, frail categories five to nine, and pre-frailty being considered category four. ${ }^{25}$

\section{Translation and adaptation process}

The translation of CFS to European Portuguese was carried out according to the World Health Organization (WHO) methodologic procedures for the validation of clinical scales, considering several steps ${ }^{26}$ The first step was to contact the author (Kenneth Rockwood) to request permission for the use of the scale in Portugal. Following the translation of the original scale (from English to Portuguese), a consensus of the Portuguese version by a panel of experts and a back-translation into English (Fig. 1) were carried out.

The translation of the scale from English to Portuguese was performed by one of the authors and another physician. After reaching consensus, the translators assessed and discussed the cultural adaptation of the Portuguese version with a panel of medical experts, to adjust this translation to the most appropriate clinical and linguistic terms. A Portuguese version was then elaborated and prepared for back-translation.

The back-translation process (Portuguese to English) was assessed by two independent professional translators, fluent in both Portuguese and English. The consensus of the back-translation and comparison with the original scale version was performed by an independent experienced healthcare consultant. Consensus was reached, and a back-translated version and the translation file (Portuguese translation and back translation) concerning the scale was sent to the author of the original scale, for assessment. After minor changes and suggestions, the European Portuguese version of the CFS was issued upon Kenneth Rockwood's approval.

In addition, in order to assess the level of comprehensibility, the translated version was examined by healthcare workers (two physicians and two nurses) working in convalescence units, who were asked about any unclear words, concepts or other elements that they were unable to understand.

Afterwards, a pilot-study was carried out by one physician and one nurse, with previous training in the administration of the CFS. This study was done based on a sample of ten individuals, representative of the target population, in order to identify any modification needed in the research protocol, as well as in the data collection procedures.

The result of all this process produced the final translated version of the CFS.

To complete the validation process, the reliability and validity of the European Portuguese version of the scale was then evaluated, as described below. In this validation study, the research protocol was applied by the same researchers who collected the data in the pilot-study.

\section{Reliability of the scale}

The reliability of a scale is measured, among others, by the test-retest evaluation, which means that when the scale is given to the same individuals twice, in an adequate interval of time, the results should be similar between applications. ${ }^{27}$ In this study, reliability was assessed by test-retest evaluation, in a non-probability sample of 51 elders, with an interval of one week between assessments.

For the evaluation of test-retest, each patient was classified in one of the nine categories of the CFS, assuming the cut-off 5 for frailty (frail if $\geq 5$; non-frail if $<5$ ) and in three degrees of dementia when there was a diagnosis.

\section{Validity of the scale}

Validity refers to ensuring that the scale is measuring what it is supposed to measure.

Convergent validity is a subset of construct validity, which is assessed by the correlation between the measure of interest and another test or other variables related with the same construct. In the present study, convergent validity was measured by calculating the correlation and the agreement between the first application of the CFS and the TFI. Therefore, the hypothesis to be tested would be the presence of a positive moderate to strong or very strong correlation between the CFS score and the TFI. A moderate to substantial or to nearly perfect agreement level between CFS and TFI score was also expected. Moreover, sensitivity, specificity and the area under the Receiver Operating Characteristics Curve (ROC) were calculated to assess the accuracy of the CFS. ${ }^{27}$

\section{Tilburg Frailty Indicator}

The TFI was developed in 2010 by Gobbens to assess psychological and social frailty in community-dwelling older adults. It is considered a well-validated and reliable instrument to measure frailty and its physical components have 
been found to show good predictive ability of adverse outcomes. ${ }^{10,12,28}$

It is a self-administered questionnaire divided into parts A and B. Part A assesses the determinants of frailty and diseases (socio-demographics, multimorbidity, life events and environment) in 10 questions. Part B assesses the components of frailty, divided into three domains: physical (with 11 items -health, weight loss, difficulty in walking, balance, hearing, vision, gripping and tiredness) psychological (with four items - memory, feeling down, anxiety and coping) and social (with four items - living alone, social isolation, and social support). In part B, 11 items have two response categories (yes/no), while four items have three (yes/no/ sometimes). However, all items are scored as zero or one. The minimum score for each domain is zero points, with a maximum score of eight for the physical domain, four for the psychological domain and three for the social domain. Each domain has a separate classification, and together they reach a final score (ranging from 0 to 15). Although the original scale has a cut-off for frailty of five, the Portuguese version of TFI has six as cut-off point, as it showed better sensitivity and specificity. In this study, we used the cut-off point of the Portuguese version (frail if $\geq 6$; non-frail if $<$ 6). ${ }^{12,28}$

\section{Statistical analysis}

Descriptive results are presented by absolute $(n)$ and relative (\%) frequencies, with 95\% confidence intervals (whenever applicable) for categorical variables, and with mean, median, standard deviation, minimum and maximum for numerical variables.

The test-retest reliability of CFS was assessed by calculating the Cohen's kappa coefficient for CFS dichotomous total score (non-frail/frail) and the ICC for the nine-point scale total (as continuous variable) according to the consistency method. ${ }^{29}$ According to the guidelines proposed by Landis and Koch ${ }^{30}$ for Cohen's kappa interpretation, a moderate agreement is considered for $0.41-0.60$, a substantial agreement for $0.61-0.80$ and a nearly perfect agreement for $0.81-1.00$ values. ICC values were interpreted as follows: < 0.50 (poor), 0.50 - 0.75 (moderate), 0.75 - 0.90 (good) and $>0.90$ excellent reliability. ${ }^{31}$

The convergent validity was explored by the correlation between the two scales (CFS and TFI) with the Spearman coefficient for total score. Correlation coefficients were interpreted as: very weak $(0-0.30)$, weak $(0.31-0.50)$, moderate $(0.51-0.70)$, strong $(0.71-0.90)$ and very strong (> $0.90) .{ }^{32}$ The agreement between scales was also assessed for frailty, using the Cohen's kappa coefficient.

Sensitivity, specificity, and ROC analysis were determined to evaluate the accuracy of the measurement for frailty. The ROC analysis results were interpreted according to the following: $<0.70$ represents low accuracy, $0.70-0.90$ moderate accuracy, and $\geq 0.90$ high accuracy. ${ }^{33}$

All statistical tests were two-tailed and assumed a significance level of $5 \%$. The statistical analysis was performed using SAS ${ }^{\circledR}$ software (version 9.4; SAS Institute Inc., Cary,
USA).

\section{RESULTS}

Out of 81 subjects recruited, a total of 30 were excluded, namely three due to age (under 65 years old), seven due to difficulty in communicating (not aware/conscious or oriented, and 20 unable to communicate) and refusal to respond to the survey. A total of 51 patients were included in the final analysis. The post-hoc power analysis indicated an approximate power of 1.00 for ICC calculations and 0.970 for spearman correlation, suggesting adequate power.

Table 1 summarizes the socio-demographic characterization of the sample. Approximately $65 \%$ of patients were female, with a mean age of $78( \pm 9)$ years old, $47.1 \%$ were widowed and $45.1 \%$ were married. Only $10 \%$ of them were living in a rural area. More than a half of patients had an

Table 1 - Socio-demographic characterization of the sample

\begin{tabular}{|c|c|}
\hline & $\begin{array}{c}\text { Total } \\
(n=51)\end{array}$ \\
\hline \multicolumn{2}{|l|}{ Gender, n (\%) } \\
\hline Male & $18(35.3 \%)$ \\
\hline Female & $33(64.7 \%)$ \\
\hline \multicolumn{2}{|l|}{ Age (years)* } \\
\hline Mean & 78.42 \\
\hline SD & 9.01 \\
\hline Median & 76.50 \\
\hline Minimum & 58.00 \\
\hline Maximum & 102.00 \\
\hline \multicolumn{2}{|l|}{ Marital status, n (\%) } \\
\hline Single & $3(5.9 \%)$ \\
\hline Married/ Living with partner & $23(45.1 \%)$ \\
\hline Separated/ Divorced & $1(2.0 \%)$ \\
\hline Widow & $24(47.1 \%)$ \\
\hline \multicolumn{2}{|l|}{ Living area, $\mathrm{n}(\%)^{*}$} \\
\hline Urban & $45(90.0 \%)$ \\
\hline Rural & $5(10.0 \%)$ \\
\hline \multicolumn{2}{|l|}{ Educational level, n (\%) } \\
\hline None & $5(9.8 \%)$ \\
\hline$\leq 4$ years & $26(51.0 \%)$ \\
\hline $5-6$ years & $7(13.7 \%)$ \\
\hline 7 - 9 years & $2(3.9 \%)$ \\
\hline $10-12$ years & $7(13.7 \%)$ \\
\hline University & $3(5.9 \%)$ \\
\hline Other & $1(2.0 \%)$ \\
\hline \multicolumn{2}{|l|}{ Retired, n (\%) } \\
\hline No & $9(17.6 \%)$ \\
\hline Yes & $42(82.4 \%)$ \\
\hline \multicolumn{2}{|l|}{ Professionally active, $\mathrm{n}(\%)$} \\
\hline No & $44(86.3 \%)$ \\
\hline Yes & $7(13.7 \%)$ \\
\hline
\end{tabular}


educational level offour or less years and only $5.9 \%$ had higher education. About $14 \%$ of the patients were professionally active and more than $80 \%$ were retired.

\section{Reliability of the CFS}

Table 2 and Fig. 2 describe the results for the test-retest of the European Portuguese version of the CFS.

In the first application of the scale (test), most patients were categorized as 'well' (21.6\%), 'managing well' (17.6\%) or 'moderately frail' (15.7\%). No patients were 'very severely frail' or 'terminally ill' although there was a higher percent-

Table 2 - Clinical Frailty Scale: test-retest results.

\begin{tabular}{|c|c|c|}
\hline \multirow[b]{2}{*}{ Clinical Frailty Scale (test), n (\%) } & \multicolumn{2}{|c|}{$\begin{array}{c}\text { Total } \\
(n=51)\end{array}$} \\
\hline & CFT (test), n (\%) & CFS (reteste), $n(\%)$ \\
\hline Very fit & $4(7.8 \%)$ & $4(7.8 \%)$ \\
\hline Well & $11(21.6 \%)$ & $11(21.6 \%)$ \\
\hline Managing well & $9(17.6 \%)$ & $9(17.6 \%)$ \\
\hline Vulnerable & $5(9.8 \%)$ & $5(9.8 \%)$ \\
\hline Mildly frail & $7(13.7 \%)$ & $6(11.8 \%)$ \\
\hline Moderately frail & $8(15.7 \%)$ & $9(17.6 \%)$ \\
\hline Severely frail & $7(13.7 \%)$ & $7(13.7 \%)$ \\
\hline Very severely frail & 0 & 0 \\
\hline Terminally ill & 0 & 0 \\
\hline \multicolumn{3}{|l|}{ Frailty cut-off, n (\%) } \\
\hline Non-frail $(<5)$ & \multicolumn{2}{|c|}{$29(56.9 \%)$} \\
\hline Frail $(\geq 5)$ & \multicolumn{2}{|c|}{$22(43.1 \%)$} \\
\hline Dementia, n (\%) & $\mathrm{n}(\%)^{*}$ & $\mathrm{n}(\%)^{* *}$ \\
\hline Mild dementia & $15(78.9 \%)$ & $13(76.5 \%)$ \\
\hline Moderate dementia & $3(15.8 \%)$ & $3(17.6 \%)$ \\
\hline Severe dementia & $1(5.3 \%)$ & $1(5.9 \%)$ \\
\hline
\end{tabular}

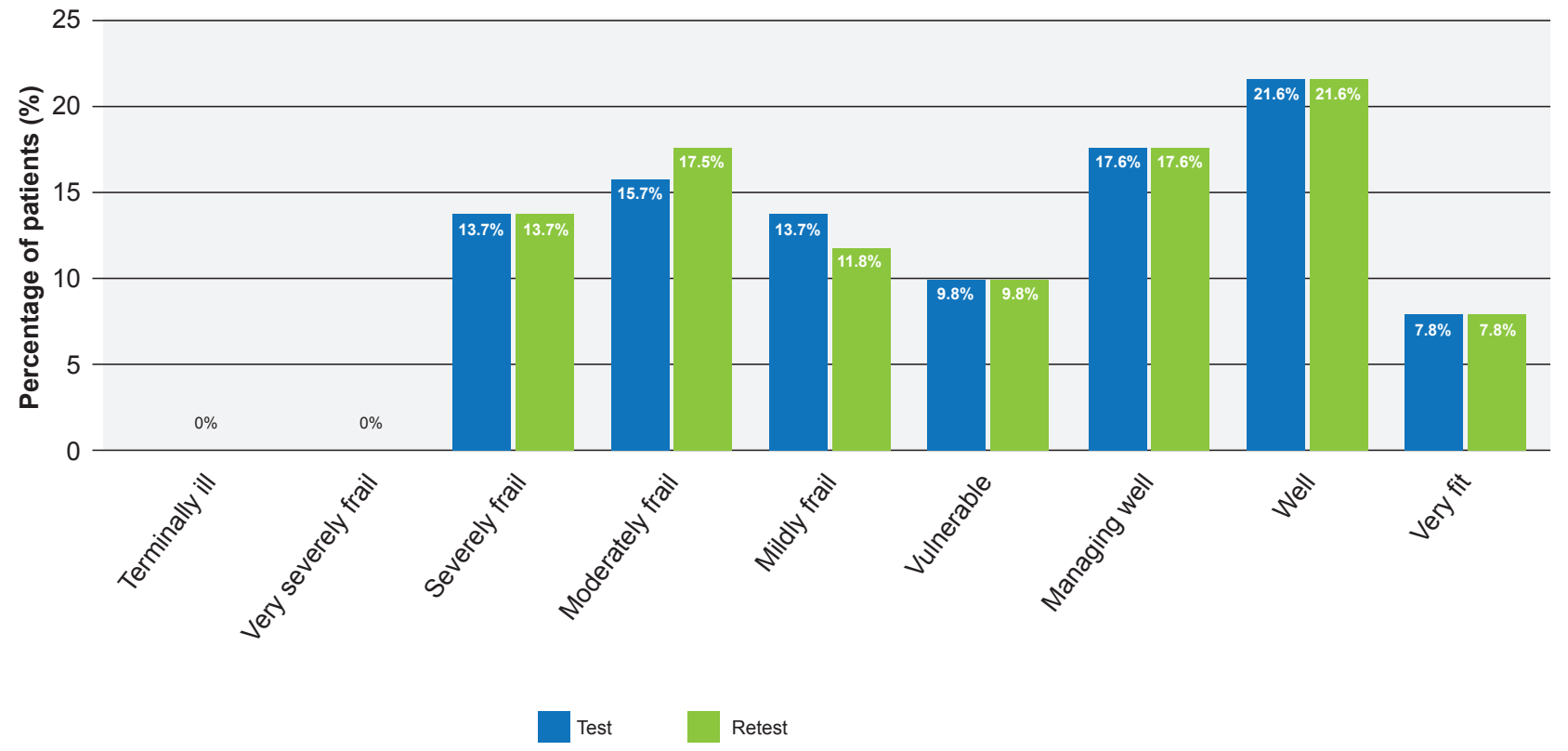

Figure 2 - The results of the Clinical Frailty Scale in test-retest assessments 
respectively). Dementia was registered in 17 patients: mild for 13 patients $(76.5 \%)$, moderate for three $(17.6 \%)$ and severe for one $(5.9 \%)$ of them.

In test-retest reliability, a Cohen's kappa coefficient of one [95\% confidence interval $(\mathrm{Cl}) 1.000$ - 1.000] was found for the total score non-frail/frail. The ICC of $0.999(95 \% \mathrm{Cl}$ 0.998 ; 0.999) was obtained for the nine-point scale total. These results showed that the CFS holds an excellent testretest reliability (Table 3 ).

\section{Validity of scale}

Descriptive results for the TFI are summarized in Table 4. Ninety-four percent of patients were born in Portugal and $62 \%$ had a monthly income between $€ 501$ and $€ 1500$. Most patients $(41.2 \%)$ believe they have a 'not healthy nor unhealthy' lifestyle, although a higher percentage of patients considers themselves to be healthy $(35.3 \%)$ compared to those who feel unhealthy $(23.5 \%)$. A third of the sample had two or more diseases or chronic disorders, and over a quarter of them $(26.5 \%)$ experienced the death of a loved one in the previous year. Also, $20.8 \%$ had a serious illness and $14.6 \%$ a loved one with a serious illness. Overall, more than $80 \%$ of the sample was satisfied with their home environment.

The components of frailty have shown mean scores of 3.45 for physical domain, 1.76 for psychological domain and 0.88 for social domain. The final score registered for the TFI was 6.06. Considering five as the cut-off point for frailty, $43.1 \%$ of patients were non-frail and $56.9 \%$ were frail.

The convergent validity of the CFS was performed by correlation of the first application of this scale with the TFI. The Spearman coefficient was $0.683(95 \% \mathrm{Cl} 0.502 ; 0.807)$ showing a statistically significant $(p<0.001)$ and a moderate correlation between the two scales. ${ }^{32}$ Cohen's kappa coefficient was $0.423(95 \% \mathrm{Cl} 0.185 ; 0.660)$, also statistically significant $(p=0.002)$ and showing a moderate agreement between the frailty/non-frailty classification of the scales. ${ }^{30}$ The results for sensitivity and specificity defined that $62.0 \%$ of patients were true positives and $81.8 \%$ were true negatives. The accuracy of the measurement determined by the ROC analysis was 0.782 , which means that there is a moderate accuracy (Table 3). ${ }^{33}$

\section{DISCUSSION}

This study aims to describe the translation and validation of the European Portuguese version of the Clinical Frailty Scale in a sample of older adults admitted to convalescence units from the National Network of Integrated Continuous Care in Northern Portugal, and followed in two outpatient clinics of social solidarity institutions.

The sample was mostly characterised by widowed elderly women with lower education levels, consistent with findings from other studies. . $^{1,15}$ Most of them were retired, but overall satisfied with their home environment. A third of patients had two or more chronic conditions. Dementia defined by CFS was identified in 19 patients and frailty was considered in $43.1 \%$ of patients, based on the CFS.

These results are consistent with the assessment determined by the TFI with mean score of 3.45 for physical domain, which confirms the weak physical condition of the patients compared to their psychological or social state, with scores of 1.76 and 0.88 , respectively. The mean total TFI score obtained in this analysis was similar to the one reported by Coelho et $a l,{ }^{12}$ for a sample with similar sociodemographic characteristics.

In the present study, the CFS showed an excellent testretest reliability. Robust results on convergent validity were also achieved, with a moderate correlation and a moderate agreement between the CFS and the TFI. The CFS also showed a moderate sensitivity and accuracy, and high specificity, providing results that allowed for the validation of the scale. These findings demonstrate that the European Portuguese version of the CFS is a reliable and valid measure of frailty in elders, which is in line with previous validations studies concerning the CFS.

Regarding validity properties, correlations between the CFS and other frailty measures were also found in the original study ${ }^{1}$ and in other validation studies. ${ }^{15,17,18}$

During 2005, in the second stage of de Canadian Study of the Health and Aging (CSHA), Kenneth Rockwood developed the CFS, ${ }^{1}$ which has demonstrated high correlation $(r=0.80 ; p<0.01)$ with the Frailty Index, confirming the convergent validity of the scale. The Frailty Index was developed in the initial stages of the CSHA, as a method of counting the clinical deficits of a patient. More specifically,

Table 3 - Reliability and validity results of the Clinical Frailty Scale (CFS)

\begin{tabular}{|c|c|c|c|c|}
\hline & Total & & $95 \% \mathrm{Cl}$ & $p$ value \\
\hline \multicolumn{5}{|l|}{ Reliability (Test-retest evaluation for CFS) } \\
\hline Intra Class Correlation (score 1 to 9 ) & 51 & 0.999 & $(0.998 ; 0.999)$ & $<0.001$ \\
\hline Cohen's kappa coefficient (non-frail/frail) & 51 & 1.000 & $(1.000-1.000)$ & $<0.0001$ \\
\hline \multicolumn{5}{|l|}{ Convergent validity } \\
\hline Correlation between CFS and TFI & 51 & $0.683^{*}$ & $(0.502 ; 0.807)$ & $<0.001$ \\
\hline Cohen's kappa coefficient & 51 & 0.423 & $(0.185 ; 0.660)$ & 0.002 \\
\hline Sensitivity & - & 0.620 & - & - \\
\hline Specificity & - & 0.818 & - & - \\
\hline ROC analysis & - & 0.782 & - & - \\
\hline
\end{tabular}

Cl: confidence interval; CFS: Clinical Frailty Scale; TFI: Tilburg Frailty Indicator, *Spearman's correlation coefficient; ROC: Receiver Operating Characteristics Curve 
Table 4 - Descriptive results for the Tilburg Frailty Indicator (TFI) (section 1 of 3)

\begin{tabular}{|c|c|}
\hline & Total \\
\hline \multicolumn{2}{|c|}{ PART A: DETERMINANTS OF FRAILTY } \\
\hline \multicolumn{2}{|l|}{ Gender, n (\%) } \\
\hline Male & $18(35.3 \%)$ \\
\hline Female & $33(64.7 \%)$ \\
\hline Total & 51 \\
\hline \multicolumn{2}{|l|}{ Age (years) } \\
\hline Mean & 78.42 \\
\hline SD & 9.01 \\
\hline Median & 76.50 \\
\hline Minimum & 58.00 \\
\hline Maximum & 102.00 \\
\hline Total & 50 \\
\hline \multicolumn{2}{|l|}{ Marital status, n (\%) } \\
\hline Single & $3(5.9 \%)$ \\
\hline Married/ Living with partner & $23(45.1 \%)$ \\
\hline Separated/ Divorced & $1(2.0 \%)$ \\
\hline Widow & $24(47.1 \%)$ \\
\hline Total & 51 \\
\hline \multicolumn{2}{|l|}{ Country of birth, $n(\%)$} \\
\hline Portugal & $47(94.0 \%)$ \\
\hline Angola & $2(4.0 \%)$ \\
\hline Cabo Verde & $1(2.0 \%)$ \\
\hline Total & 50 \\
\hline \multicolumn{2}{|c|}{ Highest level of education completed (years) } \\
\hline Mean & 7.35 \\
\hline SD & 9.96 \\
\hline Median & 4.00 \\
\hline Minimum & 0.00 \\
\hline Maximum & 70.00 \\
\hline Total & 48 \\
\hline
\end{tabular}

this index score is calculated as the proportion of potential deficits present in a given individual (in a list of 40 deficits, the score is 1 for each deficit present, 0 when they are absent, and a fraction when they are present to a limited extent. If there are 10 deficits from a total of 40 , the resulting index score will be $10 / 40=0.25) .{ }^{4}$

Chan et a/ ${ }^{17}$ performed CFS validation of the telephone version (TV) with the participation of 67 geriatric patients in a tertiary medical centre in Taipei, Taiwan. Criterion validity was achieved with weighted kappa of $0.689(p<0.0001)$ and Kendal's tau of $0.612(p<0.0001)$ between TV and PV (physician version) scores.

In a recent cross-section validation study, ${ }^{15}$ the Brazilian Portuguese language version of the CFS revealed a good convergent validity, showing significant correlations $(r=-0.663 ; p<0.0001)$ with the standard questionnaire of the 36-item Short Form Survey (SF-36), a quality of life assessment instrument, with some specific items regarding physical aspects, which are also addressed in the CFS.

The comparison of the results of the current study with findings from previous studies need some caution, as there is some heterogeneity in the methodological aspects of these studies, namely regarding the setting (hospital or community), sample (inpatients or outpatients), as well as procedures used to assess reliability and validity.

The present study has some strengths. First, this is the first validation study of the CFS in Portugal. Other instruments validated for assessing frailty in Portugal, such as the $\mathrm{TFI}^{12}$ and the GFI, ${ }^{13}$ do not have specific clinical evaluation. Secondly, a rigorous process of translation and cultural adaptation were conducted. Third, the test-retest was completed within the recommended time, with the scale applied by both healthcare professionals, and the frailty assessed directly. Fourth, the CFS identifies and ranks physical and cognitive fragility (dementia). This study also allowed for a detailed clinical characterization of a sample of elderly 
Table 4 - Descriptive results for the Tilburg Frailty Indicator (TFI) (section 2 of 3)

\begin{tabular}{|c|c|}
\hline & Total \\
\hline \multicolumn{2}{|c|}{ Net monthly household income, $\mathrm{n}(\%)$} \\
\hline$€ 250$ or less & $3(6.0 \%)$ \\
\hline$€ 251$ to $€ 500$ & $6(12.0 \%)$ \\
\hline$€ 501$ to $€ 750$ & $10(20.0 \%)$ \\
\hline$€ 751$ to $€ 1000$ & $8(16.0 \%)$ \\
\hline$€ 1001$ to $€ 1500$ & $13(26.0 \%)$ \\
\hline$€ 1501$ to $€ 2000$ & $3(6.0 \%)$ \\
\hline$€ 2001$ or more & $7(14.0 \%)$ \\
\hline Total & 50 \\
\hline \multicolumn{2}{|c|}{ Overall, how healthy would you say your lifestyle is? n (\%) } \\
\hline Healthy & $18(35.3 \%)$ \\
\hline Not healthy, not unhealthy & $21(41.2 \%)$ \\
\hline Unhealthy & $12(23.5 \%)$ \\
\hline \multicolumn{2}{|c|}{ Do you have two or more diseases and/or chronic disorders? n (\%) } \\
\hline No & $34(66.7 \%)$ \\
\hline Yes & $17(33.3 \%)$ \\
\hline \multicolumn{2}{|c|}{ Have you experienced one or more of the following events during the past year? } \\
\hline \multicolumn{2}{|c|}{ - the death of a loved one, $\mathrm{n}(\%)$} \\
\hline No & $36(73.5 \%)$ \\
\hline Yes & $13(26.5 \%)$ \\
\hline Total & 49 \\
\hline \multicolumn{2}{|c|}{ - a serious illness yourself, n (\%) } \\
\hline No & $38(79.2 \%)$ \\
\hline Yes & $10(20.8 \%)$ \\
\hline Total & 48 \\
\hline \multicolumn{2}{|c|}{ - a serious illness in a loved one, $n(\%)$} \\
\hline No & $41(85.4 \%)$ \\
\hline Yes & $7(14.6 \%)$ \\
\hline Total & 48 \\
\hline \multicolumn{2}{|c|}{ - a divorce or ending of an important intimate relationship, $n(\%)$} \\
\hline No & $48(100.0 \%)$ \\
\hline Yes & 0 \\
\hline Total & 48 \\
\hline \multicolumn{2}{|l|}{ - a traffic accident, n (\%) } \\
\hline No & $47(100.0 \%)$ \\
\hline Yes & 0 \\
\hline Total & 47 \\
\hline \multicolumn{2}{|l|}{ - a crime, n (\%) } \\
\hline No & $48(100.0 \%)$ \\
\hline Yes & 0 \\
\hline Total & 48 \\
\hline \multicolumn{2}{|c|}{ Are you satisfied with your home living environment?, n (\%) } \\
\hline No & $9(18.0 \%)$ \\
\hline Yes & $41(82.0 \%)$ \\
\hline Total & 50 \\
\hline
\end{tabular}


Table 4 - Descriptive results for the Tilburg Frailty Indicator (TFI) (section 3 of 3)

\begin{tabular}{|c|c|}
\hline & Total \\
\hline \multicolumn{2}{|c|}{ PART B: COMPONENTS OF FRAILTY } \\
\hline \multicolumn{2}{|c|}{ Score for B1 (physical domain) } \\
\hline Total & 51 \\
\hline Mean & 3.45 \\
\hline SD & 2.39 \\
\hline Median & 3.00 \\
\hline Minimum & 0.00 \\
\hline Maximum & 8.00 \\
\hline \multicolumn{2}{|c|}{ Score for B2 (psychological domain) } \\
\hline Total & 51 \\
\hline Mean & 1.76 \\
\hline SD & 1.31 \\
\hline Median & 2.00 \\
\hline Minimum & 0.00 \\
\hline Maximum & 5.00 \\
\hline \multicolumn{2}{|c|}{ Score for B3 (social domain) } \\
\hline Total & 51 \\
\hline Mean & 0.88 \\
\hline SD & 0.82 \\
\hline Median & 1.00 \\
\hline Minimum & 0.00 \\
\hline Maximum & 3.00 \\
\hline \multicolumn{2}{|l|}{ Final score } \\
\hline Total & 51 \\
\hline Mean & 6.06 \\
\hline SD & 3.64 \\
\hline Median & 6.00 \\
\hline Minimum & 0.00 \\
\hline Maximum & 13.00 \\
\hline \multicolumn{2}{|c|}{ Frailty cut-off, n (\%) } \\
\hline Total & 51 \\
\hline Non-frail $(<6)$ & $22(43.1 \%)$ \\
\hline Frail $(\geq 6)$ & $29(56.9 \%)$ \\
\hline
\end{tabular}

SD: standard deviation

patients admitted in two convalescence units and in two outpatient clinics.

Some limitations of this study must also be mentioned. There was no control of the stability of participants, which is a limitation for studying reliability. Moreover, the nonprobability sampling method and the fact that this was foursite study validation limits generalizability that could be achieved from these results.

Nevertheless, considering that the psychometric properties of this version resemble those obtained in other validation studies, these results are promising. Further research, namely longitudinal studies and with larger samples, is needed in order to better understand the complexity of frailty and to study other psychometric proprieties of this version. These studies should be also developed with the CFS in ambulatory, emergency services, hospital and primary health care consultations, with the aim of stratifying the population according to the concept of frailty and developing care plans focused on this vulnerable population. Creating platforms for patients with frailty and keeping them on a 'radar' whenever possible, so that they can return to their previous state of health, seem like good strategies to be implemented.

\section{CONCLUSION}

This study has shown that the European Portuguese version of the CFS is a reliable and valid scale. The reliability score was close to perfect, and a moderate correlation 
between the CFS and the TFI was found, as well as a moderate agreement between the frailty/non-frailty classifications. The CFS also showed a moderate accuracy result determined by the ROC analysis, good sensitivity and high specificity. The Portuguese version of the CFS delivers a psychometric evaluation that is similar to other validated versions.

These results highlight the reproducibility and consistency of the scale, which is valid for application in clinical care of the elderly Portuguese population admitted in convalescence units and followed in outpatient clinics of social solidarity institutions.

\section{ACKNOWLEDGEMENTS}

The authors want to thank all the elderly participants, Mariana Pinto, Ricardo Oliveira, who collected the data, Susana Ganhão Arranhado and Silvestre Carneiro, for being part of the expert committee.

\section{AUTHORS CONTRIBUTION}

MPP: Substantial contributions to the conception or design of the work. Acquisition, analysis and interpretation of data for the work. Drafting the work. Final approval of the version to be published. Agreement to be accountable for all aspects of the work in ensuring that questions related to the accuracy or integrity of any part of the work are appropriately investigated and resolved.

SM, LF: Substantial contributions to the conception or design of the work. Revising it critically for important intellectual content. Final approval of the version to be pub-

\section{REFERENCES}

1. Rockwood K, Song X, MacKnight C, Bergman H, Hogan D, McDowell I, et al. A global clinical measure of fitness and frailty in elderly people. CMAJ. 2005;173:489-95.

2. Morley JE, Vellas B, van Kan GA, Anker SD, Bauer JM, Bernabei R, et al. Frailty consensus: a call to action. J Am Med Dir Assoc. 2013;14:3927.

3. Xue QL, Tian J, Fried L, Kalyani R, Varadhan R, Walston J, et al. Physical frailty assessment in older women: can simplification be achieved without loss of syndrome measurement validity? Am J Epidemiol. 2016;183:1037-44.

4. Rockwood K, Mitnitski A. Frailty in relation to the accumulation of deficits. J Gerontol A Biol Sci Med Sci. 2007;62:722-7.

5. Clegg A, Young J, Iliffe S, Rikkert M, Rockwood K. Frailty in elderly people. Lancet. 2013;381:752-62.

6. Rodríguez-Mañas L, Féart C, Mann G, Viña J, Chatterji S, ChodzkoZajko W, et al. Searching for an operational definition of frailty: a delphi method based consensus statement. the frailty operative definitionconsensus conference project. Gerontol A Biol Sci Med Sci. 2013;68:627.

7. Dent E, Kowal P, Hoogendijk EO. Frailty measurement in research and clinical practice: a review. Eur J Intern Med. 2016;31:3-10.

8. Aguayo G, Donneau A, Vaillant M, Schritz A, Franco O, Stranges S, et al. Agreement between 35 published frailty scores in the general population. Am J Epidemiol. 2017;186:420-34.

9. Wei Y, McGrath PJ, Hayden J, Kutcher S. Measurement properties of tools measuring mental health knowledge: a systematic review. BMC Psychiatry. 2016;16:297.

10. Gobbens R, Assen M, Luijkx K, Wijnen-Sponselee M, Schols J. The Tilburg Frailty Indicator: psychometric properties. J Am Med Dir Assoc. 2010;11:344-55.

11. Peters L, Boter H, Burgerhof J, Slaets J, Buskens E. Construct validity of the Groningen Frailty Indicator established in a large sample of homedwelling elderly persons: evidence of stability across age and gender. lished. Agreement to be accountable for all aspects of the work in ensuring that questions related to the accuracy or integrity of any part of the work are appropriately investigated and resolved.

EM: Substantial contributions for statistical analysis and results presentation. Agreement to be accountable for all aspects of the work in ensuring that questions related to the accuracy or integrity of any part of the work are appropriately investigated and resolved.

\section{PROTECTION OF HUMANS AND ANIMALS}

The authors declare that the procedures were followed according to the regulations established by the Clinical Research and Ethics Committee and to the 2013 Helsinki Declaration of the World Medical Association.

\section{DATA CONFIDENTIALITY}

The authors declare having followed the protocols in use at their working center regarding patients' data publication.

\section{COMPETING INTERESTS}

The authors have declared that no competing interests exist.

\section{FUNDING SOURCES}

This research received no specific grant from any funding agency in the public, commercial, or not-for-profit sectors.

Exp Gerontol. 2015;69:129-41

12. Coelho T, Santos R, Paúl C, Gobbens RJ, Fernandes L. Portuguese version of the Tilburg Frailty Indicator: transcultural adaptation and psychometric validation. Geriatr Gerontol Int. 2015;15:951-60.

13. Duarte VM. Fragilidade nas pessoas idosas. [Doctoral dissertation from Instituto Ciencias Biomedicas Abel Salazar]. Porto: ICBAS; 2013.

14. Clegg A, Bates C, Young J, Ryan R, Nichols L, Teale E, et al. Development and validation of an electronic frailty index using routine primary care electronic health record data. Age Ageing. 2016;45:353-60.

15. Rodrigues M, Rodrigues I, Gomes da Silva D, Pinto J, Oliveira M. Clinical Frailty Scale: Translation and Cultural Adaptation into the Brazilian Portuguese Language. J Frailty Aging. 2021;10:38-43.

16. Abraham $P$, Courvoisier D, Annweiler $C$, Lenoir $C$, Millien $T$, Dalmaz F,et al. Validation of the clinical frailty score (CFS) in French language. BMC Geriatr. 2019;19:322.

17. Chan DC, Tsou HH, Chen CY, Chen CY. Validation of the ChineseCanadian study of health and aging clinical frailty scale (CSHA-CFS) telephone version. Arch Gerontol Geriatr. 2010;50:74-80.

18. Chong E, Chia JQ, Law F, Chew J, Chan M, Lim WS. Validating a standardised approach in administration of the Clinical Frailty Scale in hospitalised older adults. Ann Acad Med Singapore. 2019;48:115-24.

19. Theou O, Squires E, Mallery K, Lee J, Fay S, Goldstein J, et al. What do we know about frailty in the acute care setting? A scoping review. BMC Geriatr. 2018;18:139.

20. Juma S, Taabazuing MM, Montero-Odasso M. Clinical Frailty Scale in an acute medicine unit: a simple tool that predicts length of stay. Can Geriatr J. 2016;19:34-9.

21. Soll A, Szwamel K, Bujnowska-Fedak MM, Kurpas D. Frailty syndrome in community care - tips for patients and caregivers. High Sch Pulse. 2017;11:31-6.

22. Wallis SJ, Wall J, Biram RW, Romero-Ortuno R. Association of the clinical frailty scale with hospital outcomes. QJM. 2015;108:943-9.

23. Alfaadhel TA, Soroka SD, Kiberd BA, Landry D, Moorhouse P, 
Tennankore KK. Frailty and mortality in dialysis: evaluation of a clinical frailty scale. Clin J Am Soc Nephrol. 2015;10:832-40.

24. Ethun CG, Bilen MA, Jani AB, Maithel SK, Ogan K, Master VA. Frailty and cancer: implications for oncology surgery, medical oncology, and radiation oncology. CA Cancer J Clin. 2017;67:362-77.

25. Cheung A, Haas B, Ringer TJ, Mcfarlan A, Wong CL. Canadian study of health and aging Clinical Frailty Scale: does it predict adverse outcomes among geriatric trauma patients ? J Am Coll Surg. 2017;225:658-65.e3.

26. World Health Organization. Management of substance abuse Process of translation and adaptation of instruments. Geneva: WHO; 2013.

27. Keszei AP, Novak M, Streiner DL. Introduction to health measurement scales. J Psychosom Res. 2010;68:319-23.
28. Coelho T, Paúl C, Gobbens R, Fernandes L. Determinants of frailty: the added value of assessing medication. Front Aging Neurosci. 2015;7:56.

29. de Vet HC, Terwee CB, Knol DL, Bouter LM. When to use agreement versus reliability measures. J Clin Epidemiol. 2006;59:1033-9.

30. Landis JR, Koch GG. The measurement of observer agreement for categorical data. Biometrics. 1977;33:159.

31. Koo TK, Li MY. A guideline of selecting and reporting intraclass correlation coefficients for reliability research. J Chiropr Med. 2016;15:155-63.

32. Mukaka MM. A guide to appropriate use of Correlation coefficient in medical research. Malawi Med J. 2012;24:69-71.

33. Swets JA. No title signal detection theory and Roc analysis in psychology and diagnostics. Boston: Harvard Medical School; 1395 